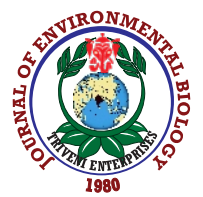

\title{
Estimating genetic diversity in Sorghum bicolor using molecular markers
}

\author{
A. Prasanth ${ }^{1}$, W. Mohanavel', D. Jaganathan ${ }^{1}$, M. Boopathi N. ${ }^{1}$, M. Manoharan ${ }^{2}$, A. Premnath ${ }^{1}$ and R. Muthurajan ${ }^{1 *}$ \\ ${ }^{1}$ Department of Plant Biotechnology, Tamil Nadu Agricultural University, Coimbatore - 641 003, India \\ ${ }^{2}$ Central Institute for Subtropical Horticulture, Lucknow - 227 107, India \\ *Corresponding Author Email : raveendrantnau@gmail.com
}

\section{Abstract}

Aim: The present study aimed at measuring the genetic diversity of a set of 219 sorghum accessions differing in their grain colour.

Methodology: About 219 diverse sorghum lines differing in their grain colour were obtained from National Bureau of Plant Genetics Resources (NBPGR), New Delhi and genotyped using 17 SSR markers. Polymorphism information content (PIC) and allele frequency were determined using PowerMarker V3.25. Clustering and factorial analysis were performed using DARwin 6.0. GenAlex version 6.5 was used to perform Principal Coordinates Analysis (PCOA) and AMOVA. Diversity analysis was performed by using Darwin.

Results: Genotyping of 219 sorghum accessions using 17 SSR markers produced a total of 399 alleles with an average PIC value of 0.85 and gene diversity of 0.87 . Highest allele frequency was observed for the marker, Xtxp 265 whereas highest major allele frequency was observed in 196 accessions for the marker, Xtxp 278. Diversity analysis divided the 219 accessions into three clusters $(1,2$ and 3$)$ and genotypes belonging to same geographical origin were found to be clustered together.
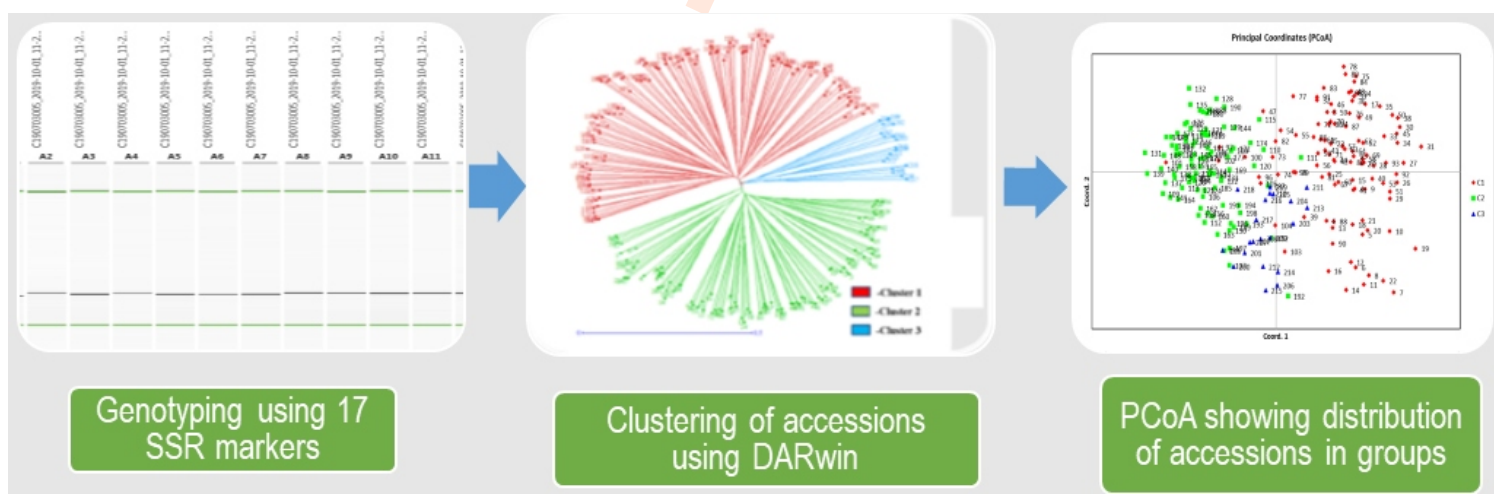

Interpretation: SSR marker based genetic diversity analysis grouped 219 sorghum accessions into three clusters. Grouping and clustering of accessions was mostly based on the geographical origins with some exceptions which may be due to cross hybridisation of accessions between countries paving a way for cross gene flow.

Key words: Factorial analysis, Genetic diversity, PCoA, Sorghum

How to cite : Prasanth, A. W. Mohanavel, D. Jaganathan, M. Boopathi N., M. Manoharan, A. Premnath and R. Muthurajan: Estimating genetic diversity in Sorghum bicolorusing molecular markers. J. Environ. Biol., 42, 1488-1494 (2021). 


\section{Introduction}

Sorghum (Sorghum bicolor (L.) Moench) is the fifth most important cereal crop worldwide after rice, wheat, maize and barley in terms of area and production (Arriola, 2005). It is rich in carbohydrates, protein, vitamins and minerals and serves as a main source of energy in Africa and South Asia (Duodu et al., 2003). It also serves as an important source of fodder and biofuel (Doggett, 1988). The genus Sorghum includes five subgenus or sections: Eu-Sorghum, Chaetosorghum, Heterosorghum, ParaSorghum and Stiposorghum (Garber, 1950). Eu-Sorghum contains all cultivated sorghum races including $S$. bicolor subsp. bicolor $(2 n=2 x=20$ chromosomes) and its wild relatives (De Wet and Harlan, 1971; Doggett, 1988). Globally, sorghum is cultivated in about 105 countries with an area of 42.14 Mha and production of around 54.34 MT (Rakshit et al., 2014). Africa contributes to half of the global sorghum production $(50.2 \%)$ followed by the Americas (32.4\%) and Asia (13.4\%) (FAOSTAT, 2018). Sorghum is highly adapted to marginal environments such as drought, salinity, water logging and heat stresses and hence, it remains as crop of choice to the rainfed farmers (ICR ISAT, 1996).

Recent advancements in food technology has made sorghum as one of the major ingredient in food industries. Sorghum contains rich amount of genetic diversity for diverse applications as food, fodder and also as a functional food. However, utilization of these conserved diversified germplasm in crop improvement is very limited due to lack of information on the genetic diversity and genetic basis of traits of nutritional importance. Large collection of sorghum germplasm is stored in international gene banks and only a selective set of germplasm are being exploited resulting in bringing narrow genetic diversity (Upadhyaya et al., 2009). Salih et al. (2016) studied the pattern of genetic diversity among sorghum accessions from East and Central Africa using 39 micro satellites markers which revealed the existence of high level of genetic diversity from the East African germplasm and suggested that these germplasm should be preserved from genetic erosion. Simple sequence repeat (SSR) markers are commonly used for assessing genetic diversity due to high level of polymorphism (Rai et al., 1999). In another study, Murray et al. (2009) utilized the genetic diversity among 125 sweet sorghum accessions and performed marker trait association of brix content and plant height using 47 SSR and 322 SNP markers. Recently, Zhu et al. (2020) performed the genetic diversity analysis of 140 sorghum accessions using 45 SSR markers and panicle traits and suggested that the broomcorn type sorghums possessed high variability in geographical origins.

Besides the agronomic advantages, sorghum is a rich source of nutrition and the grains are composed of carbohydrates

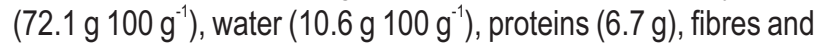
lipids (3.5 g) (USDA, 2019). Due to its nutritional facts, sorghum is highly preferred to combat malnutrition in sorghum growing developing countries as a means of low cost and sustainable option. Several studies have reported bio fortification of sorghum, especially for zinc, iron and carotenoid content (Che et al., 2016; Cruet Burgos et al., 2020; Kumar et al., 2013). The objective of the current study was to assess the genetic diversity of about 219 sorghum accessions differing in their grain colour using a set of 17 SSR markers. This diversity study will pave way to understand the genetic architecture of seed colour in sorghum and assist the development of a core collection which can be used as a potential genetic resource for association mapping of major grain nutritional/therapeutic properties in coming years.

\section{Materials and Methods}

Plant materials: A set of 219 diverse sorghum accessions originating from 15 different countries were procured from National Bureau of Plant Genetics Resources (NBPGR), New Delhi through Indian Institute of Millet Research (IIMR), Hyderabad, India. All the accessions were raised at Agricultural Research Station, Kovilpatti, Tamil Nadu, India.

Genotyping using SSR markers: Genomic DNA was extracted from the leaves of 30-day-old plants using CTAB method (Murray and Thompson, 1980). A total of 17 SSR markers were used for genotyping all the 219 accessions. PCR analysis of all the 17 SSR markers was set in a $10 \mu$ reaction consisting of 50 ng of template DNA, 0.5 pico moles of forward primer and reverse primer, $0.4 \mathrm{mM}$ dNTPs, $4 \mathrm{mM}$ of $\mathrm{MgCl}_{2}, 150 \mathrm{mM}$ of Tris $\mathrm{HCl}$ and $0.05 \mathrm{U}$ Taq polymerase. PCR amplification was performed using BIORAD C1000 Touch $^{\mathrm{TM}}$ Thermal cycler using the following PCR profile: denaturation at $94^{\circ} \mathrm{C}$ for 5 min followed by 37 cycles of $94^{\circ} \mathrm{C}$ for 30 seconds, annealing at $55^{\circ} \mathrm{C}$ for 30 seconds and extension at $72^{\circ} \mathrm{C}$ for $30 \mathrm{sec}$; with a final extension of $72^{\circ} \mathrm{C}$ for $10 \mathrm{~min}$. PCR products were resolved using QIAxcel Advanced, capillary electrophoresis (M/s. QIAGEN Inc., Germany) and allele sizes were measured precisely.

Measuring genetic diversity using genotyping data: Allelic diversity of 17 SSR markers among the 219 accessions was used for the statistical analysis. Polymorphism information content (PIC), major allele frequency, total allele count, allele frequency, heterozygosity, genetic diversity and genotype frequency were determined using Power Marker V3.25 (Liu and Muse (2005)). Clustering and factorial analysis was performed using Neighbour Joining method in DARwin version 6.0 (Perrier and JacquemoudCollet, 2006). GenAlex version 6.5 was used to perform Principal Coordinates Analysis (PCOA) and to find genetic distance between accessions (Peakall and Smouse, 2012). Analysis of Molecular Variance (AMOVA), Nei's unbiased genetic distance and other diversity parameters including number of different $(\mathrm{Na})$ and effective alleles (Ne), Shannon's Information Index (I), Observed Heterozygosity (Ho), Expected Heterozygosity (He), unbiased Expected Heterozygosity (uHe) were calculated using GenAlex by grouping the accessions based on their geographical origins. 


\section{Results and Discussion}

Genotyping of 219 accessions using 17 SSR markers produced a total of 399 alleles. Average number of allele was 23 with an average PIC value of 0.8544 and average heterozygosity of 0.0643 . Marker Xtxp 265 showed the highest PIC value of 0.9804 with the maximum number of different alleles (95), heterozygosity of 1 and highest gene diversity of 0.98 (Fig. 1). Highest allele frequency was observed for the marker, Xtxp, 265 whereas the highest major allele frequency was observed for the marker Xtxp 278 that has generated an allele which was $234 \mathrm{bp}$ and it was present in 196 accessions. Marker Xtxp 278 showed the lowest PIC value of 0.6911 with the minimum allele number of 7 and with least genetic diversity of 0.7239 (Table 1).

Exploitation of a germplasm collection can be efficiently achieved by understanding its population structure, diversity and phylogenetic relations (Basak et al., 2019). During the past, SSR markers have been proved to be an efficient tool for diversity analysis (Jarne and Lagoda, 1996). Zhu et al. (2020) and Tirfessa et al. (2020) observed a mean PIC value of 0.6 and 0.45 which were comparatively low than this present study (0.85). SSR markers used in this study showed high level of polymorphism in view of allele per locus, gene diversity and PIC value as reported earlier (Adunga, 2014; Ngugi and Onyango, 2012; Tirfessa et al., 2020; Zhu et al., 2020). This indicated the existence of greater genetic variation among the sorghum accessions from different geographical origin used in the current study.
Neighbour joining analysis using DARwin grouped the accessions into 3 major clusters (C1, C2, and C3) as mentioned in Fig. 2. Cluster $\mathrm{C} 1$ contained 105 accessions which were from Ethiopia (50), Cameroon (15), Zimbabwe (10), USA (9), Sudan (5), Chad (3), Nigeria (3), Kenya (2), South Africa (2), Swaziland (2), Japan (1), Senegal (1) and Uganda (1). Cluster C2 contained 93 accessions which were from Nigeria (26), Sudan (16), Kenya (14), South Africa (11), Uganda (9), USA (6), Chad (5), Cameroon (1), Israel (1), Japan (1), Tanzania (1) and Zimbabwe (1). A total of 21 accessions from Cameroon were clustered in Cluster C3 (Fig. 3). Cluster analysis revealed that most of the accessions were clustered and grouped based on their geographical origin. For instance, majority of accessions from Cameroon were clustered in C3, accessions from Ethiopia were mostly clustered in C1 and accessions from Kenya, Nigeria, Sudan and South Africa were clustered in C2. Such geographical based clustering of genotypes were also reported in other crops, Liu et al. (2003) observed clustering of maize accessions and (Kwak and Gepts. (2009) observed clustering of common bean accessions based on geographical origin.

The results obtained from PCoA were similar to the results of DARwin analysis. These results were used to interpret the phylogenetic relationship among accessions in a scatter plot format. Axis 1 and Axis 2 from PCoA showed a total molecular variance of $5.25 \%$ and $3.34 \%$, respectively. The genetic distance between accessions was high ranging from $42 \%$ to $67 \%$. The

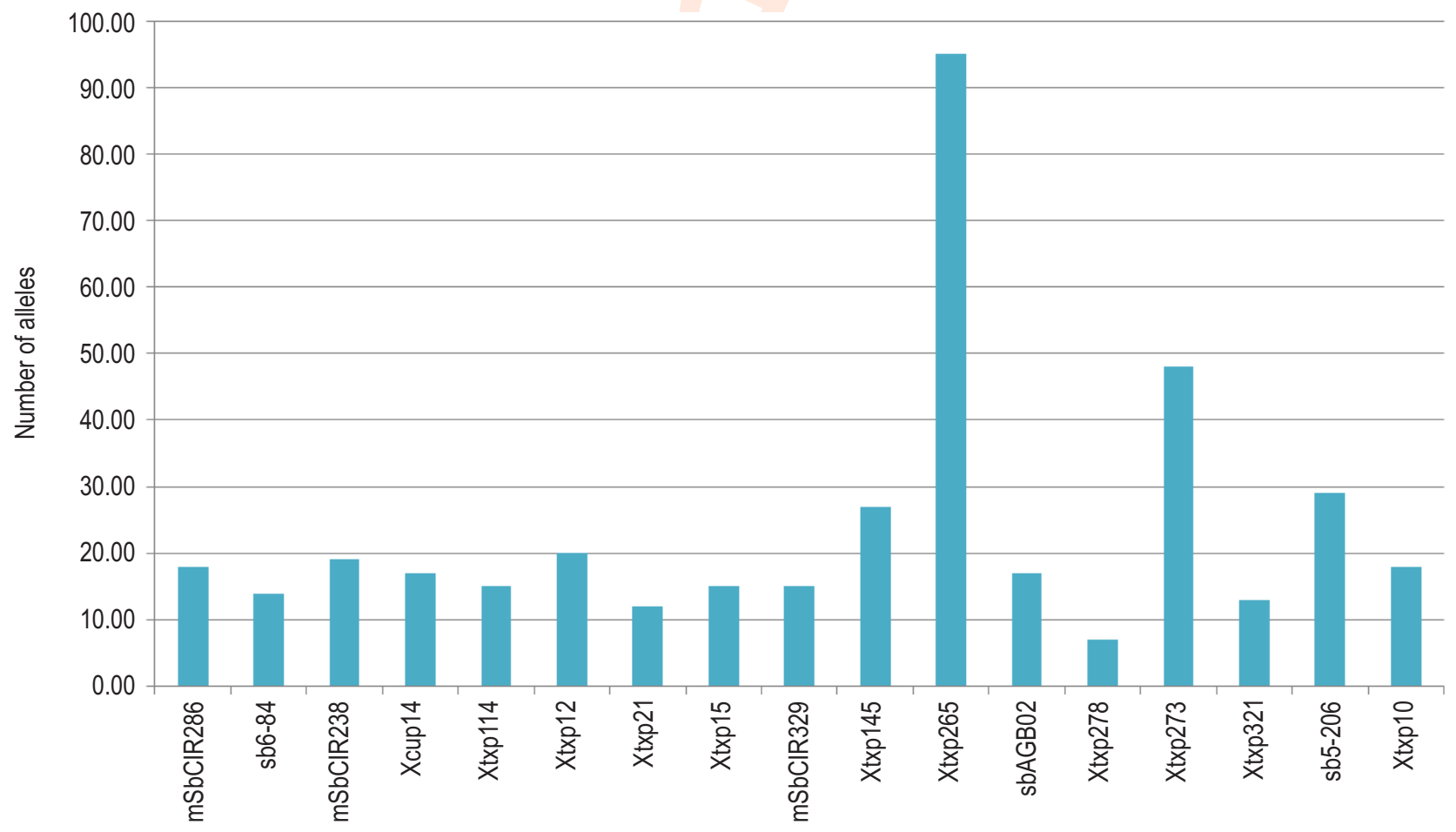

Fig. 1 : Number of alleles produced by 17 SSR markers among 219 sorghum accessions. 


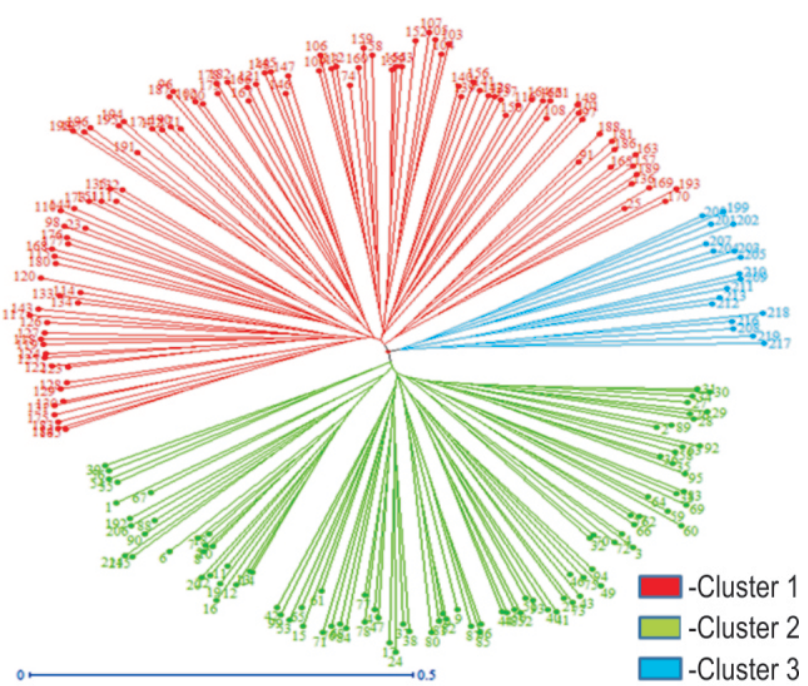

Fig. 2 : Diversity analysis of 219 sorghum accessions using DARwin: Clustering by Neighbour joining method.

genetic distance between accessions of different cluster was high when compared to the genetic distance between the accessions of same cluster. About 222 combinations between accessions had the maximum genetic distance $(67 \%)$ in which most of the combinations were between accessions of different cluster.

Sorghum diversification between regions might have started through selection, inter-specific and inter-varietal hybridization at specific locations according to the human need and to adapt to the ecological conditions (Deu et al., 2010). Nei's genetic distance was used to interpret the degree of differentiation among the population (Nei, 1986). The results of the present study indicated high genetic variation between accessions belonging to different geographical regions (Ngugi and Onyango, 2012). North-east Africa (Sudan-Ethiopia) is considered to be the origin of the genus Sorghum and considered to have high genetic variation. Mundia et al. (2019) showed a significant diversity between accessions of Sudan and Ethiopia (0.841). The results from this study also showed high genetic variation between accessions from Southern Africa (South AfricaSwaziland) and Northern Africa (Sudan-Ethiopia).

For the analyses of AMOVA and other genetic diversity parameters, accessions were grouped into 14 groups based on their geographical origins. AMOVA resulted in 10\% variance among different origins, $83 \%$ variance among individuals and

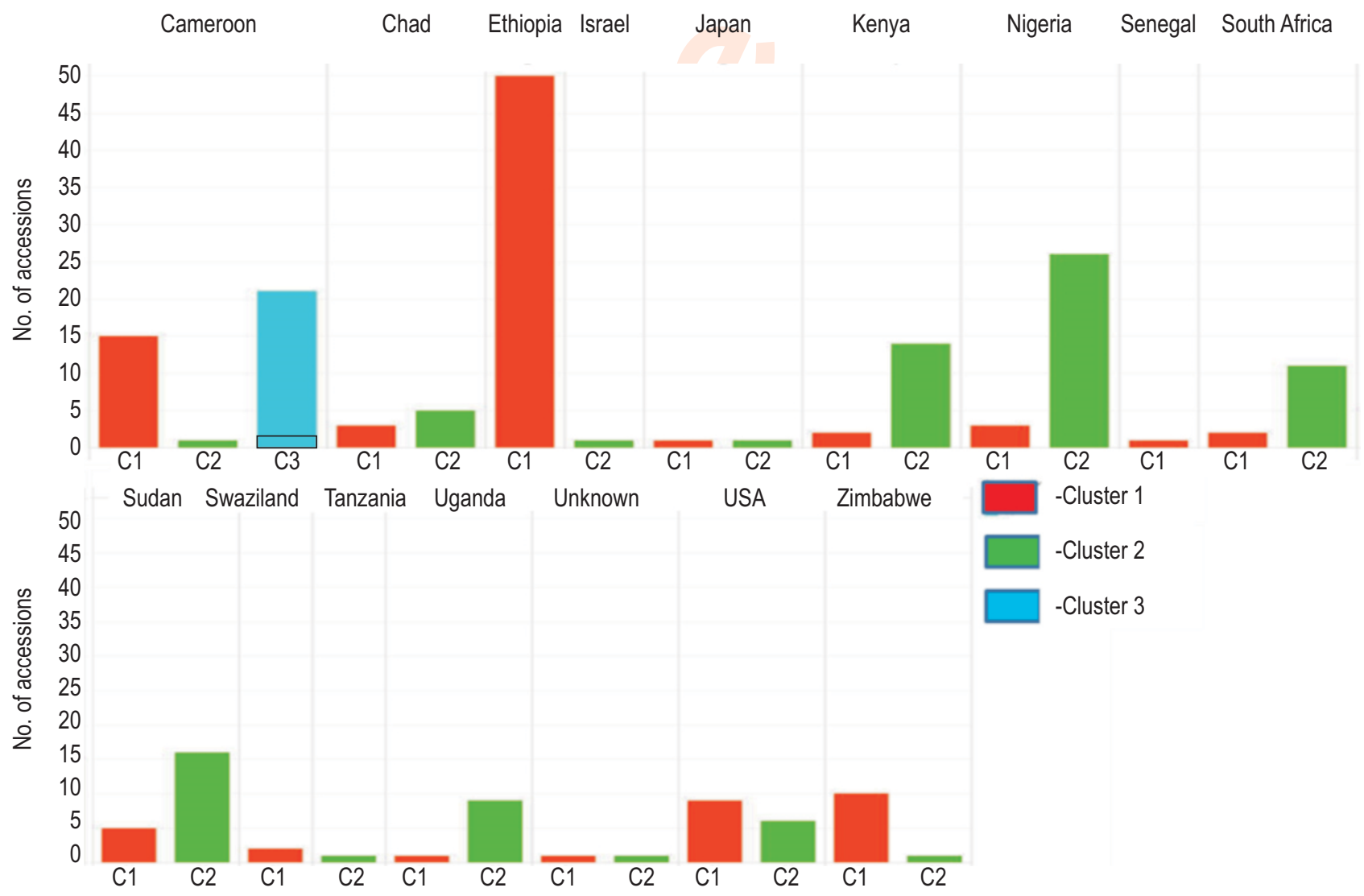

Fig. 3 : Clustering of 219 sorghum accessions based on DARwin analysis: Bar chart showing accessions from different origin assigned in different clusters. 
Table 1: Details of allelic variation generated by 17 SSR markers

\begin{tabular}{llllll}
\hline Markers & $\begin{array}{l}\text { Major (or) maximum } \\
\text { allele frequency }\end{array}$ & No. of alleles & Gene diversity & Heterozygosity & PIC \\
\hline mSbCIR286 & 0.29 & 18 & & 0.00 & 0.75 \\
Sb6-84 & 0.34 & 14 & 0.78 & 0.01 & 0.80 \\
mSbCIR238 & 0.22 & 19 & 0.82 & 0.01 & 0.88 \\
Xcup14 & 0.28 & 17 & 0.87 & 0.00 & 0.86 \\
Xtxp114 & 0.21 & 15 & 0.88 & 0.00 & 0.87 \\
Xtxp12 & 0.18 & 20 & 0.91 & 0.05 & 0.78 \\
Xtxp21 & 0.33 & 12 & 0.80 & 0.00 & 0.88 \\
Xtxp15 & 0.17 & 15 & 0.89 & 0.01 & 0.74 \\
mSbCIR329 & 0.44 & 15 & 0.76 & 0.00 & 0.93 \\
Xtxp145 & 0.12 & 27 & 0.94 & 0.00 & 0.98 \\
Xtxp265 & 0.06 & 95 & 0.98 & 1.00 & 0.87 \\
SbAGB02 & 0.22 & 17 & 0.88 & 0.00 & 0.69 \\
Xtxp278 & 0.45 & 7 & 0.72 & 0.00 & 0.95 \\
Xtxp273 & 0.10 & 48 & 0.96 & 0.00 & 0.81 \\
Xtxp321 & 0.30 & 13 & 0.83 & 0.00 & 0.94 \\
Sb5-206 & 0.11 & 29 & 0.95 & 0.00 & 0.89 \\
Xtxp10 & 0.17 & 18 & 0.90 & 0.00 & 0.85 \\
Mean & 0.24 & 23.47 & 0.87 & 0.06 & \\
\hline
\end{tabular}

Table 2 : Genetic diversity parameters of Sorghum accessions based on geographical origin

\begin{tabular}{llllllll}
\hline Origins & $\mathbf{N}$ & $\mathrm{Na}$ & $\mathrm{Ne}$ & $\mathrm{I}$ & Ho & He & uHe \\
\hline Sudan & 20.471 & 6.059 & 3.942 & 1.420 & 0.059 & 0.663 & 0.680 \\
Nigeria & 28.529 & 7.824 & 4.993 & 1.646 & 0.063 & 0.720 & 0.733 \\
Japan & 2.000 & 1.765 & 1.745 & 0.510 & 0.059 & 0.360 & 0.480 \\
Chad & 7.706 & 4.059 & 3.351 & 1.171 & 0.059 & 0.615 & 0.657 \\
Uganda & 9.412 & 5.059 & 4.049 & 1.363 & 0.059 & 0.670 & 0.708 \\
Kenya & 15.412 & 6.000 & 4.018 & 1.450 & 0.078 & 0.680 & 0.704 \\
Zimbabwe & 10.882 & 5.941 & 4.715 & 1.604 & 0.059 & 0.765 & 0.802 \\
SouthAfrica & 12.941 & 5.824 & 4.161 & 1.509 & 0.059 & 0.725 & 0.754 \\
USA & 14.882 & 6.118 & 4.258 & 1.550 & 0.078 & 0.733 & 0.758 \\
Ethiopia & 48.824 & 11.176 & 7.108 & 2.017 & 0.067 & 0.814 & 0.822 \\
Swaziland & 2.000 & 1.882 & 1.882 & 0.571 & 0.059 & 0.397 & 0.529 \\
Cameroon & 35.941 & 11.294 & 7.685 & 2.153 & 0.060 & 0.853 & 0.865 \\
Unknown & 1.765 & 1.529 & 1.529 & 0.367 & 0.059 & 0.265 & 0.373 \\
Others & 2.941 & 2.471 & 2.388 & 0.796 & 0.059 & 0.497 & 0.600
\end{tabular}

$\mathrm{N}=$ No. of Alleles; $\mathrm{Na}=\mathrm{No}$. of Different Alleles; $\mathrm{Ne}=\mathrm{No}$. of Effective Alleles; I = Shannon's Information Index; $\mathrm{Ho}=$ Observed Heterozygosity, He = Expected Heterozygosity; uHe = Unbiased Expected Heterozygosity

$7 \%$ within individuals. Genetic diversity analysis of 14 groups indicated the highest genetic diversity among the accessions from Cameroon based on Shannon's Information Index (Table 2). Nei's unbiased genetic distance between different geographical origins was performed which indicated that accessions from Swaziland and Sudan were highly diversified from this population and it also indicated that accessions from Swaziland were highly diversified compared to other geographical origins (Table 3).

Sorghum harbours greater genetic diversity for plant type, grain type, stress tolerance, nutritional content and biofuel yield which forms the basis for crop improvement program. Systematic characterization of global genetic diversity will help in identifying donors for various target traits but at the cost of huge amount of resources (Blakeney, 2002). To date, no systematic efforts have been made for assessing the sorghum genetic diversity for their nutritional content and level of phytochemicals. A systematic attempt was made in this study to assemble about 219 sorghum accessions of diverse origin differing widely in their grain colour.

AMOVA resulted in $10 \%$ molecular variance between 
Table 3 : Pairwise Matrix of Nei's Unbiased Genetic Distance between accessions based on geographical origin

\begin{tabular}{|c|c|c|c|c|c|c|c|c|c|c|c|c|c|}
\hline $\begin{array}{l}\text { Geographical } \\
\text { origin }\end{array}$ & Sudan & Unknown & Others & Nigeria & Japan & Chad & Uganda & Kenya & $\begin{array}{l}\text { Zimb- } \\
\text { abwe }\end{array}$ & $\begin{array}{l}\text { South } \\
\text { Africa }\end{array}$ & USA Ethiopia & $\begin{array}{l}\text { Swazi- } \\
\text { land }\end{array}$ & Cameroon \\
\hline Sudan & 0.000 & & & & & & & & & & & & \\
\hline Unknown & 0.524 & 0.000 & & & & & & & & & & & \\
\hline Others & 0.451 & 0.820 & 0.000 & & & & & & & & & & \\
\hline Nigeria & 0.320 & 0.599 & 0.197 & 0.000 & & & & & & & & & \\
\hline Japan & 0.666 & 1.357 & 0.601 & 0.498 & 0.000 & & & & & & & & \\
\hline Chad & 0.440 & 0.975 & 0.470 & 0.302 & 0.361 & 0.000 & & & & & & & \\
\hline Uganda & 0.360 & 0.731 & 0.569 & 0.290 & 0.629 & 0.344 & 0.000 & & & & & & \\
\hline Kenya & 0.437 & 0.739 & 0.490 & 0.313 & 0.791 & 0.461 & 0.329 & 0.000 & & & & & \\
\hline Zimbabwe & 0.417 & 0.961 & 0.620 & 0.373 & 0.672 & 0.381 & 0.462 & 0.465 & 0.000 & & & & \\
\hline South Africa & 0.705 & 1.122 & 0.932 & 0.833 & 0.985 & 0.887 & 0.705 & 0.771 & 0.570 & 0.000 & & & \\
\hline USA & 0.983 & 1.196 & 1.145 & 0.940 & 1.347 & 1.118 & 0.675 & 0.784 & 0.770 & 0.677 & 0.000 & & \\
\hline Ethiopia & 0.841 & 1.260 & 0.912 & 0.812 & 0.876 & 0.868 & 0.697 & 0.709 & 0.522 & 0.475 & 0.3100 .000 & & \\
\hline Swaziland & 1.680 & 2.000 & 1.370 & 1.323 & 1.436 & 1.276 & 1.647 & 1.244 & 1.043 & 1.155 & 1.2080 .644 & 0.000 & \\
\hline Cameroon & 0.502 & 0.831 & 0.820 & 0.712 & 1.039 & 0.868 & 0.849 & 0.829 & 0.535 & 0.633 & 0.6880 .510 & 0.889 & 0.000 \\
\hline
\end{tabular}

sorghum accessions of different origins which were less compared to $83 \%$ molecular variance among individuals. Such increased variance among individuals compared to geographical variance is often common in cross pollinated crops like sorghum (Gaudeul et al., 2000; Nybom and Bartish, 2000; Nybom, 2004; Wu et al., 2020). The observed heterozygosity (Ho) was comparatively low in this study due to its pollination type and its inbreeding nature (Muraya et al., 2010; Nei et al. 1975). Other genetic diversity parameters observed in this study were comparatively higher than the study of Ng'uni et al. (2012). PCoA grouped the accessions similar to that of clustering analysis using DARWin. Grouping and clustering of accessions was mostly based on the geographical origins with some exceptions which may be due to cross hybridisation of accessions between countries paving a way for cross gene flow. Further, core collection development will serve as representative diversity panel for the global diversity for molecular genetic studies.

\section{Acknowledgment}

Authors are grateful to NBPGR, New Delhi for providing the study material.

\section{Add-on Information}

Author's contribution : A. Prasanth: Involved in data collection, analysis, interpretation and writing first draft of the manuscript; $\mathbf{W}$. Mohanavel: Involved in data collection; D. Jaganathan: Involved in manuscript preparation; M. Boopathi N., M. Manoharan: Involved in revision of manuscript; A. Premnath: Involved in revision and final compilation of manuscript; $\mathbf{R}$. Muthurajan: Involved in conceptualization and facilitation for the study.

Research content : The research content of manuscript is original and has not been published elsewhere.

\section{Ethical approval : NotApplicable}

Conflict of interest : The authors declare that there is no conflict of interest.

\section{Data from other sources : NotApplicable}

Consent to publish : All authors agree to publish the paper in Journal of Environmental Biology.

\section{References}

Adugna, A.: Analysis of in-situ diversity and population structure in Ethiopian cultivated Sorghum bicolor (L.) landraces using phenotypic traits and SSR markers. Springerplus, 3, 212 (2014).

Arriola, P.E.: Gene flow, hybridization and introgression: Definitions and explanation. In: Gene Flow and Germplasm Management (Eds.: de Vicente MC). Topical Reviews in Agricultural Biodiversity International Plant Genetic Resource Institute, Rome, Italy, pp. 1-5 (2005).

Basak, M., B. Uzun and E. Yol: Genetic diversity and population structure of the Mediterranean sesame core collection with use of genomewide SNPs developed by double digest RAD-Seq. PIoS ONE, 14, e0223757 (2019).

Blakeney, M.: Intellectual property, biological diversity, and agricultural research in Australia. Aust. J. Agric. Res., 53, 127-147 (2002).

Che, P., Z.Y. Zhao, K. Glassman, D. Dolde, T.X. Hu, T.J. Jones, D.F. Gruis, S. Obukosia, F. Wambugu and M.C. Albertsen: Elevated vitamin $\mathrm{E}$ content improves all-trans $\beta$-carotene accumulation and stability in biofortified sorghum. Proc. Natl. Acad. Sci. U.S.A., 113, 11040-11045 (2016).

Cruet Burgos, C., S. Cox, B.P. loerger, R. Perumal, Z. Hu, T.J. Herald, S.R. Bean and D.H. Rhodes: Advancing provitamin A biofortification in sorghum: Genome wide association studies of grain carotenoids in global germplasm. Plant Genome, e20013 (2020).

De Wet, J. and J. Harlan: The origin and domestication of Sorghum bicolor. Econ. Bot., 25, 128-135 (1971).

Deu, M., F. Sagnard, J. Chantereau, C. Calatayud, Y. Vigouroux, J.L. 
Pham, C. Mariac, I. Kapran, A. Mamadou and B. Gérard: Spatiotemporal dynamics of genetic diversity in Sorghum bicolor in Niger. Theor.Appl. Genet., 120, 1301-1313 (2010).

Doggett, H.: Sorghum. $2^{\text {nd }}$ Edn., Longmans Scientific and Technical, UK (1988).

Duodu, K., J. Taylor, P. Belton and B. Hamaker: Factors affecting sorghum protein digestibility. J. Cereal Sci., 38, 117-131 (2003).

FAOSTAT: Statistical Database. Food and Agriculture Organization of the United Nations, Rome, Italy (2018).

Garber, E.D.: Cytotaxonomic studies in the genus Sorghum. Univ. Calif. Publ. Bot., 23, 283-362 (1950).

ICRISAT: The World Sorghum and Millet Economies: Facts, Trends and Outlook. Basic Foodstuffs Service, FAO Commodities and Trade Division and the Socio-economics and Policy Division, International Crops Research Institute for the Semi-Arid Tropics . ICRISAT, Andhra Pradesh; FAO, Rome (1996).

Gaudeul, M., P. Taberlet and I. Till Bottraud: Genetic diversity in an endangered alpine plant, Eryngium alpinum L. (Apiaceae), inferred from amplified fragment length polymorphism markers. Mol. Ecol., 9, 1625-1637 (2000).

Jarne, P. and P.J. Lagoda: Microsatellites, from molecules to populations and back. Trends Ecol. Evol., 11, 424-429 (1996).

Kumar, A.A., B.V. Reddy, B. Ramaiah, K.L. Sahrawat and W.H. Pfeiffer: Gene effects and heterosis for grain iron and zinc concentration in sorghum [Sorghum bicolor (L.) Moench]. Field Crops Res., 146, 86-95 (2013).

Kwak, M. and P. Gepts: Structure of genetic diversity in the two major gene pools of common bean (Phaseolus vulgaris L., Fabaceae). Theor. Appl. Genet., 118, 979-992 (2009).

Liu, K., M. Goodman, S. Muse, J.S. Smith, E. Buckler and J. Doebley: Genetic structure and diversity among maize inbred lines as inferred from DNA microsatellites. Genetics, 165, 2117-2128 (2003).

Liu, K. and S.V. Muse: PowerMarker: An integrated analysis environment for genetic marker analysis. Bioinformatics, 21, 2128-2129 (2005).

Mundia, C.W., S. Secchi, K. Akamani and G. Wang: A regional comparison of factors affecting global sorghum production: The case of North America, Asia and Africa's Sahel. Sustain., MDPI, OpenAccess J., 11, 1-18 (2019).

Muraya, M., F. Sagnard and H.K. Parzies: Investigation of recent population bottlenecks in Kenyan wild sorghum populations (Sorghum bicolor (L.) Moench ssp. verticilliflorum (Steud.) De Wet) based on microsatellite diversity and genetic disequilibria. Genet. Resour Crop. Evol., 57, 995-1005 (2010).

Murray, M.G. and W.F. Thompson: Rapid isolation of high molecular weight plant DNA. NucleicAcids Res., 8, 4321-4325 (1980).

Murray, S.C., W.L. Rooney, M.T. Hamblin, S.E. Mitchell and S. Kresovich: Sweet sorghum genetic diversity and association mapping for brix and height. Plant Genome, 2, 48-62 (2009).
Nei, M.: Definition and estimation of fixation indices. Evolution, 40, 643645 (1986).

Nei, M., T. Maruyama and R. Chakraborty: The bottleneck effect and genetic variability in populations. Evolution, 29, 1-10 (1975).

Ng'uni, D., M. Geleta, P. Hofvander, M. Fatih and T. Bryngelsson: Comparative genetic diversity and nutritional quality variation among some important Southern African sorghum accessions [Sorghum bicolor (L.) Moench]. Aust. J. Crop Sci., 6, 56-64 (2012).

Ngugi, K. and C.M. Onyango: Analysis of the molecular diversity of Kenyan sorghum germplasm using microsatellites. J. Crop Sci. Biotechnol., 15, 189-194 (2012).

Nybom, H. and I.V. Bartish: Effects of life history traits and sampling strategies on genetic diversity estimates obtained with RAPD markers in plants. Perspect. Plant Ecol. Evol. Syst., 3, 93-114 (2000).

Nybom, H.: Comparison of different nuclear DNA markers for estimating intraspecific genetic diversity in plants. Mol. Ecol., 13, 1143-1155 (2004).

Peakall, R. and P.E. Smouse: GenAIEx 6.5: genetic analysis in Excel. Population genetic software for teaching and research - An update. Bioinformatics, 28, 2537-2539 (2012).

Perrier, X. and J.P. Jacquemoud-Collet: DARwin Software (2006).

Rai, K., D. Murty, D. Andrews and P. Bramel-Cox: Genetic enhancement of pearl millet and sorghum for the semi-arid tropics of Asia and Africa. Genome, 42, 617-628 (1999).

Rakshit, S., K. Hariprasanna, S. Gomashe, K. Ganapathy, I. Das, O. Ramana, A. Dhandapani and J. Patil: Changes in area, yield gains, and yield stability of sorghum in major sorghum-producing countries, 1970 to 2009. Crop Sci., 54, 1571-1584 (2014).

Salih, S.A., L. HersIman, M.T. Labuschange and A.H. Mohammed: Assessment of genetic diversity of sorghum [Sorghum bicolor (L.) Moench] germplasm in East and Central Africa. World J. Microbiol. Biotechnol., 1, 113-120 (2016).

Tirfessa, A., T. Tesso, A. Adugna, H. Mohammed and D. Kiambi: Genetic diversity among Ethiopian sorghum [Sorghum bicolor (L.) Moench] gene bank accessions as revealed by SSR markers. African $J$. Biotech., 19, 84-91 (2020).

Upadhyaya, H., R. Pundir, S. Dwivedi, C. Gowda, V.G. Reddy and S. Singh: Developing a mini core collection of sorghum for diversified utilization of germplasm. Crop Sci., 49, 1769-1780 (2009).

USDA: National nutrient database for standard reference legacy release: Full report (all nutrients) (2019).

Wu, Q., F. Zang, Y. Ma, Y. Zheng and D. Zang: Analysis of genetic diversity and population structure in endangered Populus wulianensis based on 18 newly developed EST-SSR markers. Glob. Ecol. Conserv., 24, e01329 (2020).

Zhu, M., J. Chen, N. Yuyama, L. Luo, X. Xiao, Y. Lv, Y. Liu and H. Cai: Genetic diversity and population structure of Broomcorn sorghum investigated with simple sequence repeat markers. Trop. Plant. Biol., 13, 62-72 (2020). 